\title{
INTER-MARKETS VOLATILITY SPILLOVER IN U.S. BITCOIN AND FINANCIAL MARKETS
}

\author{
Muhammad Owais QARNI, Saqib GULZAR*, Syeda Tamkeen FATIMA, \\ Majid Jamal KHAN, Khurram SHAFI \\ Department of Management Science, COMSATS University Islamabad, \\ Wah Campus, Wah Cantt, Pakistan
}

Received 04 January 2019; accepted 27 May 2019

\begin{abstract}
This paper investigates the volatility spillover dynamics between U.S. Bitcoin and financial markets from July 19, 2010 to December 29, 2017. Diebold and Yilmaz (2012) volatility spillover index, Barunik, Kocenda, and Vacha (2017) Spillover Asymmetry Measure, and Barunik and Krehlik (2018) frequency connectedness methodologies are applied to investigate the time varying dynamics of volatility spillover among U.S. Bitcoin and financial markets. The findings of the study indicate the presence of low level of integration and contagion between U.S. Bitcoin and financial markets. Asymmetric nature of volatility spillover is also detected. The connectedness among the U.S. Bitcoin and financial markets is found to be concentrated at high frequency, suggesting that markets process information rapidly. Moreover, the turbulence in Bitcoin market will have insignificant effect on U.S. financial markets. This non-contagion nature of Bitcoin markets provides significant risk hedging and diversification benefits for domestic and foreign investors in the U.S.
\end{abstract}

Keywords: bitcoin, stock market, volatility spillover, spillover asymmetry measure, frequency connectedness, foreign exchange market.

JEL Classification: G11, G15.

\section{Introduction}

The rapidly evolving global crypto-currency market is catching the attention of active researchers and practitioners all over the world and has emerged as a fascinating field of study. Due to the economical venue for trading, crypto-currencies reached a market share of $41 \%$ in 2017 (Dwyer, 2015; Katsiampa, 2017). Recent developments in the Bitcoin market due to the announcement of crypto-currency futures' trading by CBOE Global market on December 7,2017 , observed Bitcoin prices reached a record high of $\$ 20,089$ and market capitalization

\footnotetext{
${ }^{\star}$ Corresponding author. E-mail: saqibgulzar@ciitwah.edu.pk
} 
of $\$ 326.141$ billion within ten days ${ }^{1}$. Bitcoin being the most popular and widely accepted crypto-currency, with growing market capitalization, is seen as a potential investment vehicle for many investors around the world. It acts both as medium of exchange and store of value thereby providing an attractive addition in investment portfolio (Dyhrberg, 2016a). Bitcoin is gaining importance as an investment alternative due to similar hedging characteristics to other conventional financial instruments (Richardson, 2014). This paper assesses the success of Bitcoin as a hedging instrument by studying the spillover relationship between Bitcoin and other conventional financial assets. The knowledge of contagion provides valuable information regarding the level of integration between different financial markets. Highly integrated financial markets around the world were massively disrupted during global financial crisis (2008) due to spillover effects (B. Kim, H. Kim, \& Lee, 2015). The importance of measuring spillovers between US Bitcoin and financial markets is significant to understand its hedging capabilities and ability to withstand financial downturns. Moreover, the presence of speculative bubble and increasing efficiency due to investors' growing interest in the Bitcoin markets (Nadarajah \& Chu, 2017; Urquhart, 2017) provides motivation for investigating volatility spillover between U.S. Bitcoin and financial markets.

This paper contributes to the emerging literature on Bitcoin in three-fold. Employing the Diebold and Yilmaz (2012), Barunik et al. (2017) Spillover Asymmetry Measure, and Barunik and Krehlik (2018) frequency connectedness methodologies; firstly, this paper provides empirical evidence on the dynamics of asymmetric volatility spillover among U.S. Bitcoin and financial markets. Secondly, it identifies the net transmitter and net receivers of volatility spillover among the U.S. Bitcoin and financial markets. Thirdly, it investigates the net pair-wise directional spillover across the U.S. Bitcoin, foreign exchange, bond, stock and commodity markets. The dynamic frequency connectedness of the U.S. Bitcoin and financial markets is also investigated to uncover the dynamics of volatility spillovers at high and low frequencies. Moreover, recent developments in the USA Bitcoin and foreign exchange markets have highlighted the significance of measuring and monitoring the spillover dynamics across U.S. Bitcoin and financial markets. The finding of the study will provide significant insight to investors, policy makers and academic researchers by uncovering the influence for presence of Bitcoin as an alternative investment on other financial markets. By quantifying interconnectedness relationship of Bitcoin with each financial market a better understanding of future spillover and contagion can be gained, that can be used for formulating educated investment strategies of whether to include Bitcoin in investment portfolio or not.

The rest of paper is organised as follows, section 1 presents reviews of the published literature; section 2 explains the methodology, section 3 presents descriptive of data, while section 4 presents the results and discussion. Conclusion of the study is given at the end.

\section{Literature review}

Contagion among financial markets has been has been extensively studied in the past research literature (Gulzar, Kayani, Feng, Ayub, \& Rafique, 2019; Qarni \& Gulzar, 2018; Yarovaya,

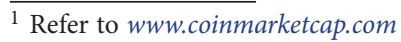


Brzeszczyński, \& Lau, 2016; Raghunathan, 2015; Yusoff \& Sabit, 2015; Antonakakis, 2012; Diebold \& Yilmaz, 2012; Bubak, Kočenda, \& Žikeš, 2011; Ehrmann, Fratzscher, \& Rigobon, 2011; Aktan, Korsakienè, \& Smaliukiene, 2010; Brunnermeier \& Pedersen, 2008; King \& Wadhwani, 1990). Due to the frequent episode of crisis (Asian financial crisis, Global financial crisis, European sovereign debt crisis, etc.) the importance of studying contagion among financial markets is further increased. The spread of contagion among the financial markets during the sub-prime crisis provide a good illustration of how a downfall in one financial market can affect other financial markets. Brunnermeier and Pedersen (2008) explained how a drop in one financial market can affect the overall financial market liquidity and asset prices in other financial markets. King and Wadhwani (1990) explained the existence of contagion among financial market as a result of investors' inference regarding price changes in other financial markets, which subsequently affects investment behavior. Kodres and Pritsker (2002) recognized that default of one financial market forces investors in other financial markets to rebalance their risk position and reduce their investment. These reductions in investment cause reduction in the liquidity of the overall financial markets.

Bitcoin has attracted a large number of investors due to its high liquidity, low cost, speed and ease of transaction. Due to the speculative nature of Bitcoin investment, spillover and contagion to other financial markets are feared as Phillips and Yu (2011) identified speculation and financial contagion to be closely related. Cheah and Fry (2015) and Cheung, Roca, and $\mathrm{Su}$ (2015) considered Bitcoin market to be a bubble accumulating market, which can burst anytime in the near future therefore instigating a fear of spillover. Researchers have valued Bitcoin to replicate the role of financial institutions (Kerner, 2014), as it provides an alternative to paper money and consequently hedges for investors in economies with unstable inflation (Richardson, 2014). Dyhrberg (2016b) considered Bitcoin as an investment instrument like gold and other investment alternatives to enhance portfolio diversification. Kurihara and Fukushima (2017) also identified the inter-link between Bitcoin and other financial assets, stating that price efficiency in Bitcoin market can enhance the coordination channel through foreign exchange market to attract fundamentals. Other examples of contagion between Bitcoin and financial markets can be deduced by looking at the former's usage mechanism. Baur, Hong, and Lee (2018) identify Bitcoin to affect U.S. foreign exchange market if it is used as a medium of exchange to purchase goods and services. Similarly, if Bitcoin is used as a medium of investment, the stock, bond and commodity markets will be affected by it. Selgin (2015) recognized Bitcoin as synthetic commodity money, sharing the features of gold and U.S. dollars. Similarly, Bouri, Jalkh, Molnár, and Roubaud (2017a) classified Bitcoin as a hybrid asset sharing the characteristics of precious metals and currency. The authors also identified Bitcoin as uncorrelated with traditional financial markets and thus provide useful diversification benefits. In addition, Demir, Gozgor, Lau, and Vigne (2018) provide evidence for short term hedging capabilities of Bitcoin in period of turbulence. Guesmi, Saadi, Abid, and Ftiti (2018) analysed Bitcoin hedging capabilities and suggested that Bitcoin provides hedging benefits in short position.

Despite the importance gained by Bitcoin as an investment alternative, literature on contagion between Bitcoin and financial markets is scarce. The growth of crypto-currencies of which Bitcoin is the most prominent, can cause contagion in other markets, if Bitcoin market 
decline. The decline in Bitcoin market can create liquidity issues and increase risk aversion of investors, causing a reduction in investment for other financial markets. European Banking Authority recognized the unregulated environment in the crypto-currency market and the risk of losses that prevails (Authority, 2014). Action Task Force also highlighted the illegal use of funds, due to unregulated system of crypto-currency markets (Force, 2014). Despite these questions raised on the legality and regulatory framework of crypto-currency markets, researchers have classified Bitcoin as a safe investment with hedging capabilities (Dyhrberg, 2016a; Dyhrberg, 2016b; Bouri, Molnár, Azzi, Roubaud, \& Hagfors, 2017b). Dyhrberg (2016a) showed that Bitcoin possesses hedging properties for dollar and UK stock market, as gold possesses. In contrast Bouri et al. (2017b) examined connectedness between Bitcoin and the world equity indices, bonds, oil, gold, the general commodity index and the US dollar index and found limited evidence for hedging capabilities of Bitcoin. In another study Bouri, Gupta, Tiwari, and Roubaud (2017c) established Bitcoin hedging capabilities against global uncertainty in the short term.

In light of the literature review, mixed evidence has been found for the hedging and portfolio diversification capabilities of Bitcoin as an alternative investment. The present study has made an effort to fill the existing research gap by empirical investigation of volatility spillover between U.S. Bitcoin and financial markets with three primary objectives. Firstly, it provides empirical evidence on the dynamics of asymmetric volatility spillover among U.S. Bitcoin and financial markets. Secondly, it identifies the net transmitter and net receivers of volatility spillover and thirdly, it investigates the net pair-wise directional spillover across the U.S. Bitcoin, foreign exchange, bond, stock and commodity markets. It also uncovers the changes in dynamics of volatility spillover in the full sample period of low and high price volatility in the Bitcoin market. In addition, dynamic frequency connectedness of the U.S. Bitcoin and financial is also investigated to uncover the dynamics of volatility spillovers at high and low frequency.

\section{Methodology}

\subsection{Generalized variance decomposition}

Diebold and Yilmaz (2012) generalized Vector Auto Regressive (VAR) methodology that eliminate the dependence of results on ordering of variables is applied to analyse the volatility spillover behaviour among the U.S. Bitcoin and financial markets. Consider N-variable VAR (p) that is covariance stationary,

$$
x_{t}=\sum_{i=1}^{p} \Psi_{t} x_{t-i}+\varepsilon_{t},
$$

where $\varepsilon_{t}$ is an independently and identically distributed vector of error terms and

$$
x_{t}=\sum_{i=0}^{\infty} C_{i} \varepsilon_{t-i},
$$

represents the moving average, where $C_{i}$ are $N \times N$ coefficient matrices obeying the recursion $C_{i}=\theta_{1} C_{i-1}+\theta_{2} C_{i-2}+\ldots .+\theta_{p} C_{i-p}$, where $C_{0}$ is an identity matrix with $C_{i}=0$ for $i<0$. Own variance contribution to $\mathrm{H}$-step ahead forecast error variance in $x_{i}$ is due to shock to 
$x_{i}$, for $i=1,2, \ldots . N$, and cross spillover contribution, to H-step ahead forecast error variance in $x_{i}$ is due to shock to $x_{j}, i, j=1,2, \ldots . N$, such that $j \neq i$.

The KPPS H-step ahead forecast error variance (Pesaran \& Shin, 1998; Koop, Pesaran, \& Potter, 1996) is computed as,

$$
\gamma_{i j}^{g}(H)=\frac{\sigma_{i i}^{-1} \sum_{h=0}^{H-1}\left(e_{i}^{\prime} C_{h} \Theta e_{i}\right)^{2}}{\sum_{h=0}^{H-1}\left(e_{i}^{\prime} C_{h} \Theta C_{h}^{\prime} e_{i}\right)},
$$

where $\Theta$ denotes variance matrix for $\varepsilon, \sigma_{i i}$ denotes the standard deviation of the error term for equation $i$ and $e_{i}$ denotes the selection vector with one as the $i$ th element and zero otherwise. The row sum of variance decomposition does not equal to 1 , because the shock to each variable is not orthogonalized.

$$
\sum_{j=1}^{N} \gamma_{i j}^{g}(H) \neq 1 .
$$

To compute the spillover index we normalize each entry of variance decomposition matrix by row/column sum as:

$$
\gamma_{i j}^{g}(H)=\frac{\gamma_{i j}^{g}(H)}{\sum_{j=1}^{N} \gamma_{i j}^{g}(H)}
$$

By construction, $\sum_{j=1}^{N} \gamma_{i j}^{g}(H)=1$ and $\sum_{i . j=1}^{N} \gamma_{i j}^{g}(H)=N$.

The total volatility spillover is computed as:

$$
S^{g}(H)=\frac{\sum_{\substack{i, j=1 \\ i \neq j}}^{N} \gamma_{i j}^{g}(H)}{\sum_{i . j=1}^{N} \gamma_{i j}^{g}(H)} \times 100=\frac{\sum_{\substack{i, j=1 \\ i \neq j}}^{N} \gamma_{i j}^{g}(H)}{N} \times 100 .
$$

The directional spillover to market $i$ from all other markets is computed as:

$$
S_{i,}^{g}(H)=\frac{\sum_{\substack{j=1 \\ i \neq j}}^{N} \gamma_{i j}^{g}(H)}{\sum_{j=1}^{N} \gamma_{i j}^{g}(H)} \times 100 .
$$

Similarly, the directional spillover from market $i$ to all other markets is computed as:

$$
S_{, i}^{g}(H)=\frac{\sum_{\substack{j=1 \\ i \neq j}}^{N} \gamma_{j i}^{g}(H)}{\sum_{j=1}^{N} \gamma_{j i}^{g}(H)} \times 100 .
$$


The net spillover for market $i$ is calculated as the difference between the total spillover to and from all other markets as:

$$
S_{i}^{g}(H)=S_{, i}^{g}(H)-S_{i,}^{g}(H) .
$$

The net pairwise spillover between markets $i$ and $j$ is computed as the difference between total spillover transmitted from market $i$ to $j$ and total spillover transmitted from $j$ to $i$.

\subsection{Spillover Asymmetry Measure}

In contrast to Diebold and Yilmaz (2012), to measure the spillover asymmetry we employ Barunik et al. (2017) using a $2 \mathrm{~N}$-variable VAR (p) by decomposing each volatility series into positive and negative volatilities. The Spillover Asymmetry Measure (SAM) is defined as the difference between the positive and negative volatility spillover. To calculate the SAM first we sum the corresponding row/column of the $2 N \times 2 N$ spillover matrix calculated by standard Diebold and Yilmaz (2012) method and exclude main diagonal of the $2 N \times 2 N$ spillover matrix and the two diagonals in the $N \times N$ sub-matrices on the lower left and the upper right of the $2 N \times 2 N$ main matrix. The idea of SAM was introduced by Barunik, Kocenda, and Vacha (2015), however, Barunik et al. (2017) extended their methodology by including positive and negative volatilities in single VAR model of $2 \mathrm{~N}$ variables.

The SAM with H-step ahead forecast at time $t, S A M_{2 N}^{H}$, is defined as the difference between volatility spillovers due to positive and negative volatilities for all markets. The SAM for directional TO spillover is defined as:

$$
S A M_{2 N}^{H}=S_{i,}^{g}(H)-S_{i+N}^{g},(H) .
$$

Similarly, the SAM for directional FROM spillover can be calculated (for details see Barunik et al., 2017).

\subsection{Frequency connectedness}

In order to analyse the frequency connectedness of the U.S. Bitcoin and financial markets we employed the Barunik and Krehlik (2018) methodology that employed spectral representations of variance decomposition method of Dew-Becker and Giglio (2016) to estimate unconditional connectedness in time frequency. The notion of frequency connectedness relations in time frequency domain was first introduced by Barunik and Krehlik (2016) and was extended by Barunik and Krehlik (2018).

Considering the spectral behaviour of series $X_{t}$ to decompose generalized impulse response function as:

$$
S_{x}(w)=\sum_{h=0}^{\infty} E\left(X_{t} X_{t-h}\right) e^{-i h w}=\Psi\left(e^{i h w}\right),
$$

where $w$ denotes the frequency, $\infty$ denotes infinite horizon connectedness, $\Psi\left(e^{-i h w}\right)=\sum_{h=0}^{\infty} \Psi_{h} e^{-i h w}$ (Barunik \& Krehlik, 2016). On a particular frequency $w$ the unconditional generalized forecast error variance decomposition (GFVED) is calculated as: 


$$
(\Theta(w))_{i, j}=\frac{\sigma_{j j}^{-1} \sum_{h=0}^{\infty}\left(\Psi\left(e^{-i h w}\right) \sum\right)_{i, j}^{2}}{\sum_{h=0}^{\infty}\left(\Psi\left(e^{-i h w}\right) \sum \Psi\left(e^{i h w}\right)\right)_{i, i}} .
$$

Equation (12) can be standardized as:

$$
(\Theta(w))_{i, j}=\frac{(\Theta(w))_{i, j}}{\sum_{j=1}^{k}(\Theta(w))_{i, j}} .
$$

Barunik and Krehlik (2016) proposed an accumulative connectedness table over an arbitrary frequency band $d=(a ;, b)$, expressed as:

$$
\left(\Theta_{d}\right)_{i, j}=\int_{a}^{b}(\Theta(w))_{i, j} d w .
$$

The overall connectedness within a frequency band $d$ can be expressed as:

$$
C^{d}=\frac{\sum_{i=1, i \neq j}^{k}\left(\Theta_{d}\right)_{i, j}}{\sum_{i, j}\left(\Theta_{d}\right)_{i, j}}=1-\frac{\sum_{i=1}^{k}\left(\Theta_{d}\right)_{i, i}}{\sum_{i, j}\left(\Theta_{d}\right)_{i, j}} .
$$

A value of $C^{d}$ close to unity indicates strong connections within the spectral band $d=(a ;, b)$. The within from connectedness measures the contribution of one market $(i \neq j)$ to another market $i$ on the spectral band $d$, which can be expressed as:

$$
C_{i \leftarrow}^{d}=\sum_{j=1, i \neq j}^{k}\left(\Theta_{d}\right)_{i, j} .
$$

The within to connectedness measures the contribution to one market $(i \neq j)$ from another market $i$ on the spectral band $d$, which can be expressed as:

$$
C_{i \rightarrow}^{d}=\sum_{j=1, i \neq j}^{k}\left(\Theta_{d}\right)_{j, i} .
$$

The total connectedness $C$ can be obtained by $S^{g}(H)=\sum_{d} C^{d}$ (Diebold \& Yilmaz, 2012).

\section{Data and descriptive statistics}

The data for U.S. Bitcoin price index retrieved from Coindesk Bitcoin price index (Coindesk, 2017) and financial markets (U.S. 10 years notes futures, USD index futures, Thomson Reuters Core commodity CRB excess return and S\&P 500 index) retrieved from investing price indices (Investing, 2017) consists of 2,721 observations dated from July 19, 2010 to December 29, 2017. Both tranquil and volatile periods for U.S. Bitcoin and financial markets are included in the sample period. The zero return on non-synchronized holidays depicts the 
actual returns for the non-trading day (Yarovaya et al., 2016). Therefore, the data for nonsynchronized holidays were taken as the previous day prices, giving zero returns on nonsynchronized holidays. The normalized high, low, and close prices are used to calculate the daily volatility for each market (Rogers \& Satchell, 1991) as:

$$
\sigma^{2}=P_{h, t}\left(P_{h, t}-P_{c, t}\right)+P_{l, t}\left(P_{l, t}-P_{c, t}\right)
$$

where $P_{h, t}$ is high price, $P_{l, t}$ is low price and $P_{c, t}$ is closing price at day $t$.

To measure SAM, we decomposed each volatility series to positive and negative volatilities, giving us a total of ten series for 5 variables. The descriptive statistics (Table 1) shows the presence of negative mean volatilities for U.S. Bitcoin and financial markets. The median, minimum, maximum and standard deviation statistics indicate that U.S. Bitcoin market prices are more volatile than other U.S. financial markets. All the series are heteroskedastic and abnormally distributed as indicated by the $\mathrm{ARCH}$, skewness, kurtosis and JB statistics. The ADF statistics are significant for all series, showing the presence of stationarity.

Table 1. Descriptive statistics

\begin{tabular}{|l|c|c|c|c|c|}
\hline & Bitcoin & Bond & Forex & Commodity & Stock \\
\hline Mean & -0.05936 & -0.00053 & -0.0008 & -0.00211 & -0.00769 \\
\hline Median & -0.01211 & -0.00184 & -0.00048 & -0.00247 & -0.01052 \\
\hline Maximum & 10.11859 & 0.104218 & 0.136307 & 0.206441 & 0.482382 \\
\hline Minimum & -5.98563 & -0.05497 & -0.12656 & -0.23062 & -0.43535 \\
\hline Std. Dev. & 0.488688 & 0.016106 & 0.021976 & 0.04308 & 0.063367 \\
\hline Skewness & -1.7253 & 0.388181 & -0.1544 & 0.106023 & 0.440517 \\
\hline Kurtosis & 117.7162 & 4.454802 & 4.814763 & 4.462762 & 7.456999 \\
\hline Jarque-Bera & 1492795 & 308.1747 & 384.0552 & 247.592 & 2339.32 \\
\hline ADF & -5.76356 & -22.8137 & -28.7598 & -28.1717 & -26.7095 \\
\hline ARCH(5) & 601.377 & 515.431 & 211.031 & 635.866 & 904.069 \\
\hline
\end{tabular}

Note: The statistics are significant $1 \%$ level of significance.

\section{Results and discussion}

\subsection{Volatility spillover index}

The volatility spillover index in Table 2 represents the average spillover among U.S. Bitcoin and financial markets during the sample period. The U.S. Stock market is considered the most integrated market with other U.S. financial markets as it receives (15.6\%) and transmits (18.5\%), the highest volatility spillover among the selected U.S. markets. The U.S. Bitcoin market receives $(0.9 \%)$ and transmits $(1.2 \%)$, the lowest volatility spillover among the selected U.S. markets. While the volatility spillover to Bitcoin market from other markets ranges from $0.09 \%$ to $0.31 \%$, with lowest spillover experienced from bond market $(0.09 \%)$ whereas highest spillover observed from stock market $(0.31 \%)$. On average, the inter-market volatil- 
ity spillover during the sample period is $10.6 \%$. The analysis indicates the presence of low bidirectional and total spillover among the U.S. Bitcoin and financial markets as discussed by Diebold and Yilmaz (2012) for the four U.S. financial markets (Stocks, Bonds, commodities, and foreign exchange markets). Moreover, it can be seen that the integration level of U.S. financial markets have changed over time. Diebold and Yilmaz (2012) found bond market to be the highest receiver and transmitter of volatility spillover during the period 1999 to 2010, whereas in our analysis, stock market indicates the highest spillover to and from other markets. Similarly, the average spillover was found to be $12.6 \%$, which is higher than $10.6 \%$ in our analysis. This low level of integration in U.S. Bitcoin and financial markets provides significant diversification benefits for the speculative investors.

Table 2. Volatility spillover index

\begin{tabular}{|l|c|c|c|c|c|c|}
\hline & Bitcoin & Bond & Forex & Commodity & Stock & From others \\
\hline Bitcoin & 99.06 & 0.09 & 0.26 & 0.28 & 0.31 & 0.9 \\
\hline Bond & 0.30 & 88.97 & 1.71 & 1.55 & 7.47 & 11.0 \\
\hline Forex & 0.21 & 1.83 & 89.87 & 5.34 & 2.75 & 10.1 \\
\hline Commodity & 0.60 & 1.46 & 5.24 & 84.76 & 7.94 & 15.2 \\
\hline Stock & 0.05 & 6.79 & 2.35 & 6.41 & 84.39 & 15.6 \\
\hline Contribution to others & 1.2 & 10.2 & 9.6 & 13.6 & 18.5 & 52.9 \\
\hline $\begin{array}{l}\text { Contribution } \\
\text { including own }\end{array}$ & 100.2 & 99.1 & 99.4 & 98.3 & 102.9 & $10.6 \%$ \\
\hline
\end{tabular}

\subsection{Rolling window analysis - total spillover}

The 200-day Rolling windows analysis in Figure 1 depicts the time varying patterns of average volatility spillover among the U.S. Bitcoin and financial markets. A glimpse of figure 1 appears to be responsive to domestic and international events and even to news announcements. The $1^{\text {st }}$ phase of drastic increase in the volatility spillover among the U.S. Bitcoin and financial markets was observed during the second quarter of 2011 which indicates the turbulence in the U.S. financial markets due to the onset of Euro-zone crisis and energy crisis because of civil war in Libya. During the $3^{\text {rd }}$ quarter of 2011, the volatility spillover among the selected markets further increased due to crash of worldwide stock markets as a result of contagion from Euro-Zone crises and Debt ceiling crisis in the United States. The second phase of increased volatility spillover can be seen in May 2012 as the severity of Euro-zone crisis reached its peak. The second quarter of 2013 demonstrates the $3^{\text {rd }}$ phase of increased volatility spillover among the selected markets due to U.S. FRB taper Tantrum and Cyprus financial downturn. During this time, significant rise in the Bitcoin price has been observed. The Bitcoin prices increased significantly during the Cyprus crisis, as investors' preferences toward Bitcoins became favourable. The $4^{\text {th }}$ phase of increased volatility spillover is depicted during the year 2014 due to oil prices shock financial stress transmission, the Russian crisis, the Crimean crisis and the worsening conditions of the Euro-zone troubled economies. The Shanghai Stock market crash (May 2015) and European stock market collapse (August 24, 2015) further increased the volatility spillover among the U.S. Bitcoin and financial markets. 
During 2016 the U.S. financial markets indicate increasing trend in volatility spillover with eventual spikes in response to global economic events such as Brexit announcement on June 23 and Chinese reform initiative in August 2016. The year 2017 depicts a declining trend in the volatility spillover among the U.S. Bitcoin and financial markets due to stability of global financial markets in 2017. Volatility spillover spike in January 2017 indicates the response of U.S. financial markets to the election of Donald Trump as the $45^{\text {th }}$ U.S. president and worldwide protest against Donald Trump. The spike in May 2017 represents the ransom-ware cyber-attack that affected computers all around the world. Volatility spike in June 2017 indicates the uncertainty in the U.S. financial markets caused by the U.S. announcement to withdraw from the Paris climate agreement. A volatility spillover spike in August 2017 indicates the financial stress due to Hurricane Irma and Hurricane Maria that struck the Caribbean and the United states. The November 2017 volatility spillover spike is due to the uncertainty in the financial markets over the German newspaper "Suddeutsche Zeitung" publishing 13.4 million documents related to offshore financial activities of politicians, corporate giants and business leaders. All the above-mentioned evidences indicate high responsive attitude of volatility spillover among U.S. Bitcoin and financial markets to various international and domestic event with varying magnitudes.

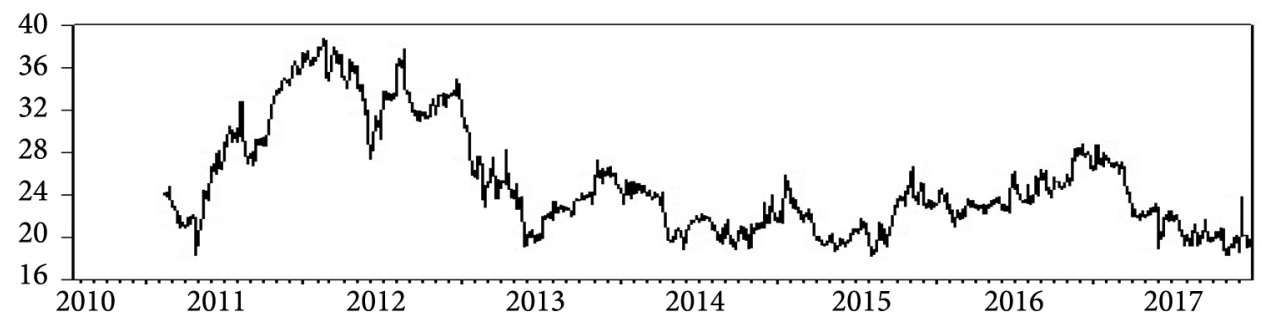

Figure 1. Average spillover index - U.S. bitcoin and financial markets

\subsection{Directional volatility spillover}

The 200-day rolling window directional volatility spillover from U.S. Bitcoin and financial markets, as shown in figure 2, depicts the time varying pattern in volatility spillover from U.S. Bitcoin and financial markets during tranquil and turbulent periods. In calm periods, the volatility spillover from Bitcoin market is below $10 \%$, that reaches above $25 \%$ during periods of turbulence. For U.S. financial markets, the volatility spillover in calm periods is below $20 \%$ but reaches $50 \%$ during turbulent periods. Except for the Bitcoin market, all individual U.S. financial markets' directional volatility spillover transmission to other U.S. financial markets depicts an increasing trend starting in the $2^{\text {nd }}$ quarter of 2011 till the $1^{\text {st }}$ quarter of 2012 (Euro-zone crisis). The U.S. Bitcoin market volatility transmission to other U.S. financial markets remained below 30\% mark during the $1^{\text {st }}$ and $2^{\text {nd }}$ quarter of 2011 and declined significantly during the $3^{\text {rd }}$ and $4^{\text {th }}$ quarter of 2011 . The volatility spillover transmission from U.S. Bitcoin market to all other U.S. financial markets remained well below $30 \%$ during the entire sample period, with eventual spikes. The U.S. bond and foreign exchange markets' volatility spillover to other markets has increased considerably in $3^{\text {rd }}$ quarter of 2013 
(U.S. FRB taper Tantrum and Cyprus financial downturn). On the other hand, U.S. commodity and stock markets' volatility transmission to other U.S. financial markets declined till $2^{\text {nd }}$ quarter of 2014. U.S. stock market has been the highest transmitter of volatility spillover to other U.S. financial markets during the episode of European stock market collapse (August $24,2015)$. In contrast, the U.S. bond and foreign exchange markets have been the significant transmitter of volatility spillover to other U.S. financial markets due to Brexit announcement on June 23, 2016 and Chinese reform initiative in August 2016.

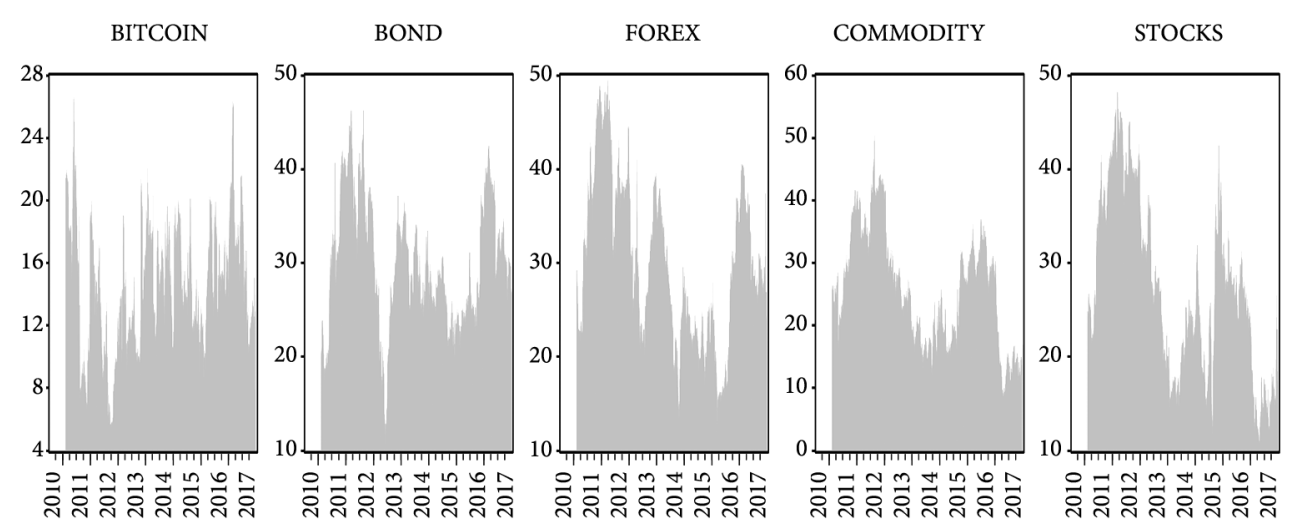

Figure 2. Directional volatility spillover from U.S. bitcoin and financial markets

The time varying patterns of volatility spillover to the U.S. Bitcoin and financial markets indicates the non-constant behaviour of volatility spillover as presented in Figure 3. The volatility spillover to the Bitcoin market lies below $10 \%$ during the tranquil period, whereas during turbulence period, it increases up to $35 \%$. In contrast, the volatility spillover to the U.S. financial markets is higher than the Bitcoin markets during calm and turbulence periods. During calm periods the volatility spillover to the financial markets is below $20 \%$ and during turbulence periods, reaches above $40 \%$. Both stock and foreign exchange markets exhibit the most responsive behaviour to global financial events with volatility spillover exceeding $50 \%$. During the onset of euro-zone crisis 2011, the U.S. stock market has been ranked the highest recipient of volatility spillover from all other U.S. markets. On the contrary, Bitcoin is considered the least receiver of volatility spillover from all other U.S. financial markets during the entire sample period. The U.S. bond and foreign exchange markets received significant volatility spillover from other U.S. financial markets in 2013 due to U.S. FRB taper Tantrum and Cyprus financial downturn, in addition to Brexit announcement on June 23, 2016 and Chinese reform initiative (August 2016).

\subsection{Net volatility spillover}

The net volatility spillover identifies the net transmitter and net receivers of volatility during the sample period as shown in Figure 4, whereas Figure 5 demonstrates time varying net pairwise volatility spillover between U.S. Bitcoin and financial markets. The dynamics of U.S. Bitcoin and financial markets as net transmitter and net receiver, changes during tranquil and turbulence periods. At the onset of euro-zone crisis in 2011, commodity market has 

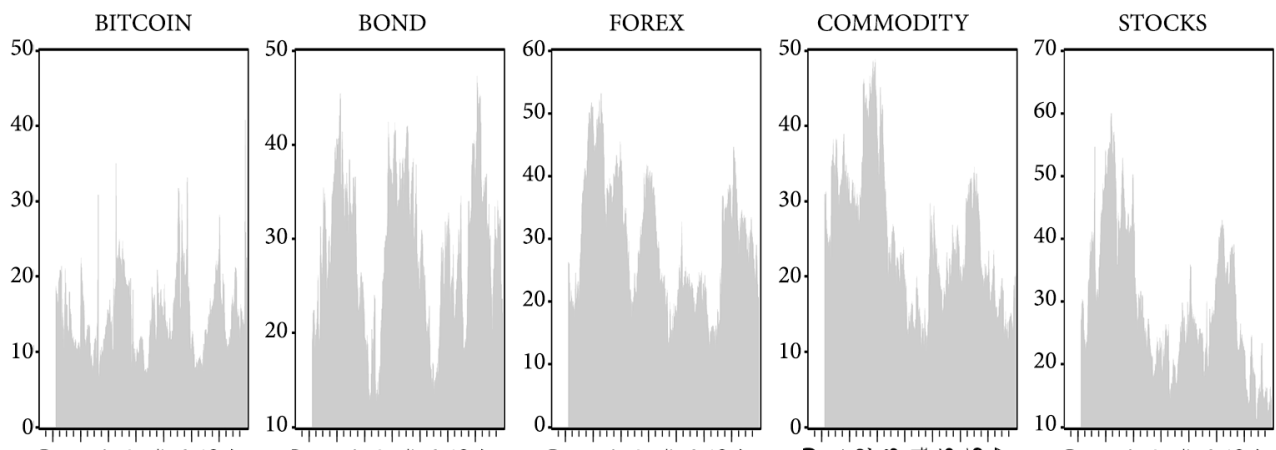

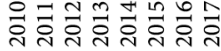

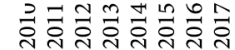

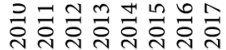

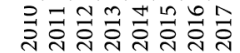

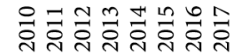

Figure 3. Directional volatility spillover to U.S. bitcoin and financial markets
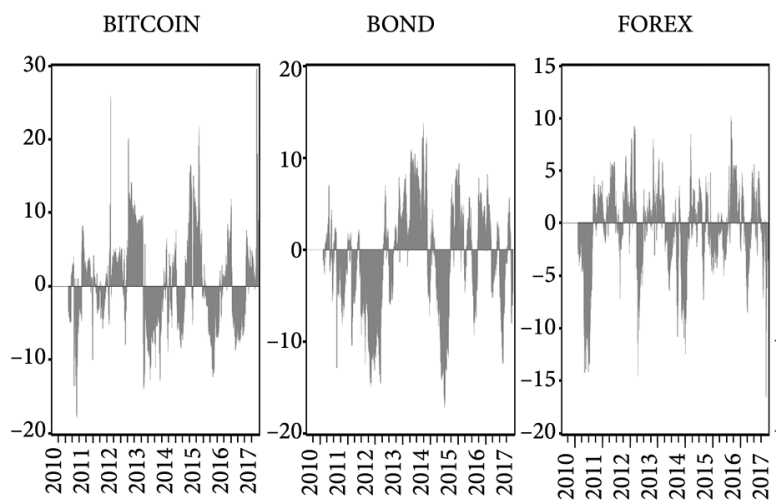

COMMODITY

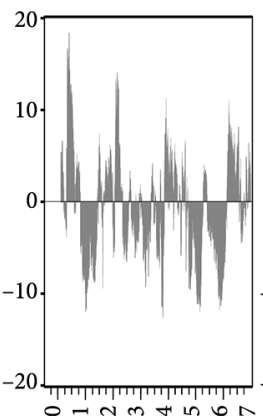

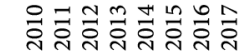

STOCKS

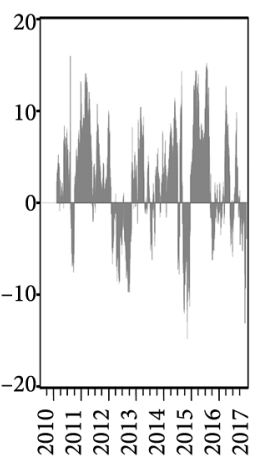

Figure 4. Net volatility spillover, U.S. bitcoin and financial markets
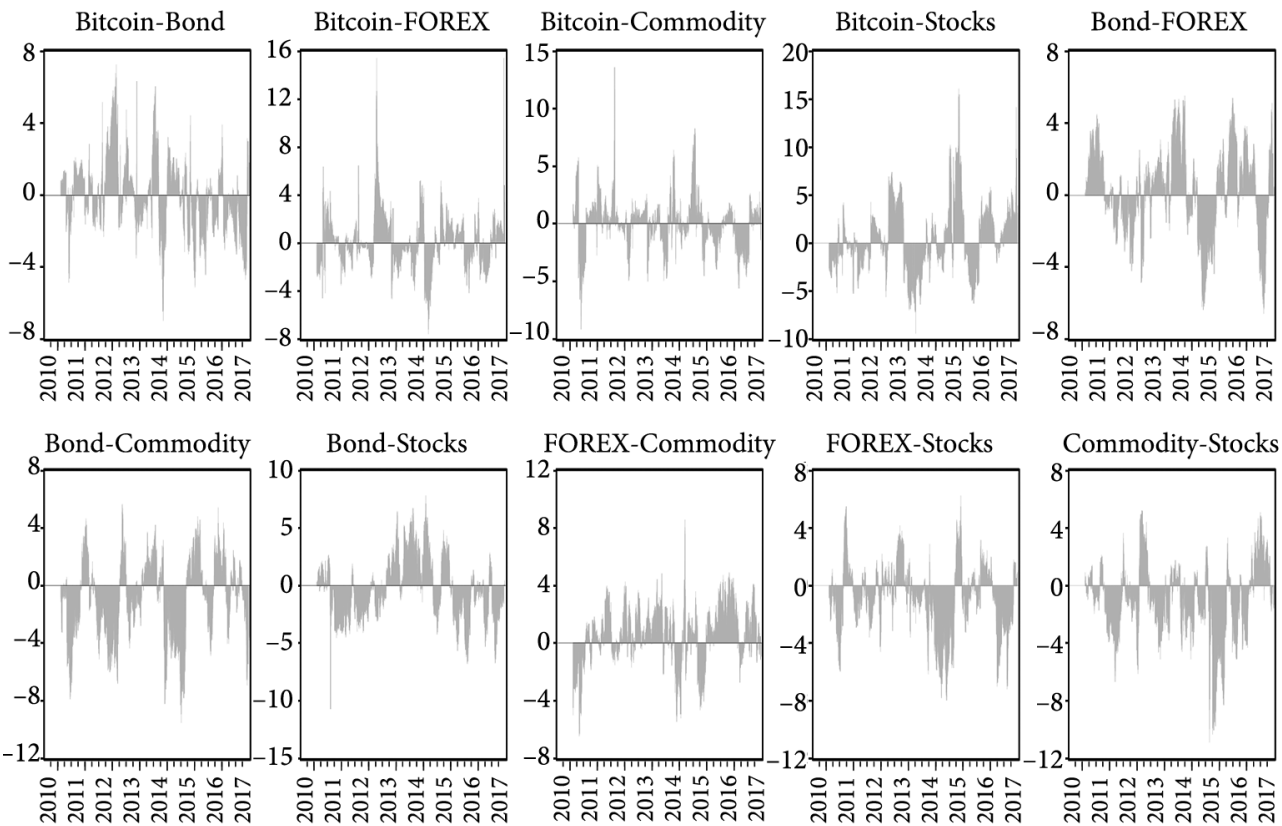

FOREX-Stocks

Commodity-Stocks
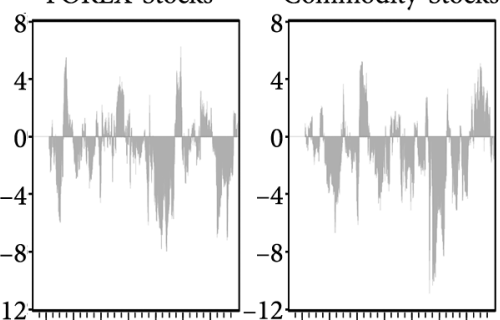

Figure 5. Net pairwise volatility spillover 
been ranked the highest net transmitter of volatility spillover to other U.S. financial market (Figure 4). The highest volatility spillover from U.S. commodity market during 2011 occurred to U.S. bond market (Figure 5). In contrast, the U.S. foreign exchange market during 2011 has been ranked the top net receiver of volatility spillover as shown in Figure 4, with highest spillover being transmitted by U.S. bond market as depicted in Figure 5 during the same time. During 2013 U.S. FRB Taper Tantrum and Cyprus financial downturn, Bitcoin market has been the highest transmitter and bond market has been the highest recipient of volatility spillover (Figure 4). The highest spillover from the U.S. Bitcoin market is transmitted to U.S. bond market and the highest volatility spillover received by the U.S. bond market is experienced from the U.S. commodity market (Figure 5). This was the time when Bitcoin prices started gaining value because of increased investors' interest.

During the Russian crisis in 2014, bond market has been ranked the highest transmitter of volatility spillover to other markets and commodity market has been considered the highest recipient of volatility spillover from other markets (Figure 4). During this period, U.S. foreign exchange market and commodity market could be seen as the receiver of highest volatility spillover from U.S. bond market as shown in Figure 5. Chinese and European stock markets turbulences in 2015 have contributed to significant increase of volatility spillover to U.S. financial markets, indicating U.S. Bitcoin market to be the highest transmitter of volatility to other U.S. financial markets and the U.S. bond market to be the highest receiver of volatility spillover from other U.S. financial markets (Figure 4). During this period, the highest spillover from U.S. Bitcoin market was transmitted to the U.S. stock market and the highest volatility spillover received by U.S. bond market is observed from the U.S. foreign exchange market as is obvious from Figure 5.

Brexit announcement on June 23, 2016 and Chinese reform initiative in August 2016, created significant impact in context of volatility spillover in which U.S. stock market has been considered the top transmitter of volatility spillover to other U.S. financial markets; whereas U.S. commodity market is the highest receiver of volatility spillover from other U.S. financial markets with reference to Figure 4. During this period, Figure 5 depicts the highest volatility spillover transmitted to the U.S. commodity market by U.S. stock market. In year 2017, several macroeconomic events (election of Donald Trump as the $45^{\text {th }}$ U.S. president and worldwide protest against Donald Trump, ransom-ware cyber-attack, U.S. announcement to withdraw the Paris climate agreement, Hurricane Irma and Hurricane Maria that struck the Caribbean and the United states, and German newspaper "Süddeutsche Zeitung" publishing 13.4 million documents related to offshore financial activities of politicians, corporate giants and business leaders) could be seen more or less contributing towards volatility spillover in the U.S. Bitcoin and financial markets. In this context, U.S. commodity market has been ranked the top transmitter of volatility spillover to other U.S. financial markets and U.S. bond market has been considered the highest receiver of volatility spillover from other U.S. financial markets according to Figure 4. Whereas Figure 5 represents the highest volatility spillover from U.S. commodity market to U.S. stock market and the highest volatility spillover to the U.S. bond market is observed from U.S. foreign exchange market. 


\subsection{Asymmetric connectedness of U.S. Bitcoin and financial markets}

The SAM reveals striking results about the asymmetric connectedness of U.S. Bitcoin and financial markets. Table 3 tells that disaggregation of volatility into positive and negative volatilities enhance the average spillover $(11.2 \%)$ during the period. The results point out the presence of asymmetry in the volatility spillover dynamics among U.S. Bitcoin and financial markets. In order to investigate the time varying nature of directional SAM we employ 200 days rolling window analysis (Figure 6 and Figure 7).

Table 3. Volatility spillover table for the $2 \mathrm{~N}$-dimensional VAR model with positive and negative volatilities

\begin{tabular}{|c|c|c|c|c|c|c|c|c|c|c|c|}
\hline & 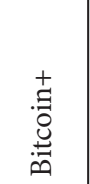 & 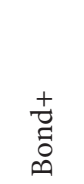 & $\begin{array}{l}+ \\
\text { 芯 } \\
\text { 苛 }\end{array}$ & 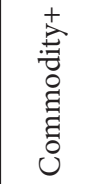 & 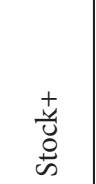 & 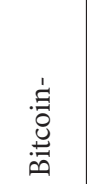 & 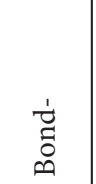 & 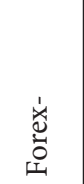 & 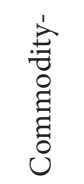 & $\begin{array}{l}\frac{\dot{y}}{u} \\
\dot{0}\end{array}$ & 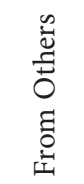 \\
\hline Bitcoin+ & 94.14 & 0.13 & 0.70 & 0.43 & 0.13 & 2.38 & 0.17 & 0.17 & 1.20 & 0.56 & 3.48 \\
\hline Bond+ & 0.39 & 72.18 & 0.18 & 0.61 & 2.75 & 0.06 & 16.43 & 2.82 & 0.75 & 3.83 & 11.40 \\
\hline Forex+ & 0.10 & 0.35 & 75.16 & 1.86 & 0.70 & 0.11 & 1.85 & 14.70 & 3.56 & 1.62 & 10.14 \\
\hline Commodity+ & 0.32 & 0.57 & 1.70 & 69.81 & 4.34 & 0.08 & 1.07 & 3.57 & 15.98 & 2.56 & 14.21 \\
\hline Stock+ & 0.05 & 2.02 & 0.52 & 4.03 & 68.59 & 0.12 & 5.43 & 2.02 & 2.22 & 14.99 & 16.42 \\
\hline Bitcoin- & 1.17 & 0.40 & 0.15 & 0.48 & 0.09 & 96.87 & 0.02 & 0.12 & 0.61 & 0.09 & 1.96 \\
\hline Bond- & 0.15 & 16.68 & 1.18 & 0.88 & 4.78 & 0.18 & 72.48 & 0.18 & 0.67 & 2.81 & 10.84 \\
\hline Forex- & 0.27 & 2.59 & 13.57 & 3.75 & 2.77 & 0.20 & 0.48 & 74.12 & 1.58 & 0.66 & 12.31 \\
\hline Commodity- & 2.01 & 0.55 & 3.20 & 14.89 & 3.13 & 0.25 & 0.65 & 1.62 & 68.52 & 5.16 & 16.59 \\
\hline Stock- & 0.13 & 3.30 & 1.53 & 2.46 & 18.79 & 0.09 & 2.74 & 0.60 & 3.61 & 66.74 & 14.46 \\
\hline $\begin{array}{l}\text { Contribution } \\
\text { to others }\end{array}$ & 3.42 & 9.91 & 9.14 & 14.50 & 18.69 & 1.11 & 12.41 & 11.11 & 14.20 & 17.31 & 111.81 \\
\hline $\begin{array}{l}\text { Contribution } \\
\text { including own }\end{array}$ & 99.94 & 98.52 & 99.00 & 100.29 & 102.27 & 99.15 & 101.57 & 98.81 & 97.61 & 102.84 & $11.2 \%$ \\
\hline
\end{tabular}

Asymmetric directional volatility spillover among the U.S. Bitcoin and financial markets (Figure 6 and Figure 7) reveals that the first phase of asymmetry occurred during the second quarter of 2011 due to the onset of Euro-Zone crisis and energy crisis because of civil war in Libya. Bitcoin, bond and commodity market received net positive spillover whereas Foreign exchange and stock markets received net negative volatility spillover from U.S. Bitcoin and financial markets. During the same period Bitcoin, Bond and foreign exchange market transmitted net negative volatility spillover to U.S. Bitcoin and financial markets, whereas commodity and stock market transmitted net positive volatility spillover to other U.S. markets. The second phase of asymmetry in volatility spillover can be seen from May 2012 as the severity of Euro-Zone crisis peaked. During this phase Bitcoin, bond, commodity and stock markets received (transmitted) net negative volatility spillover from (to) other U.S. 

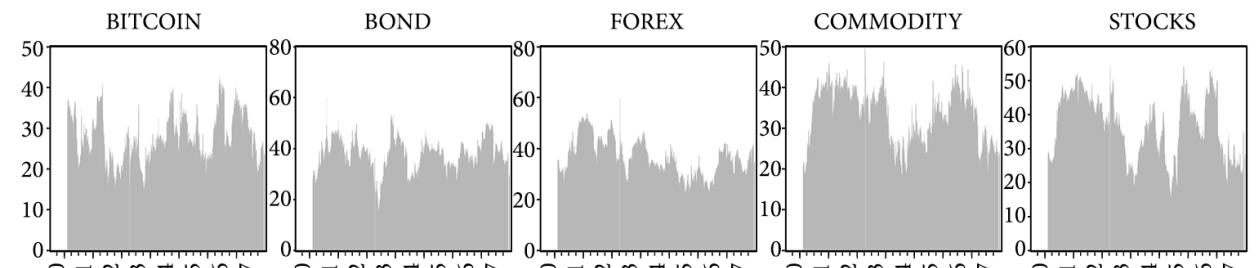

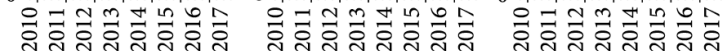
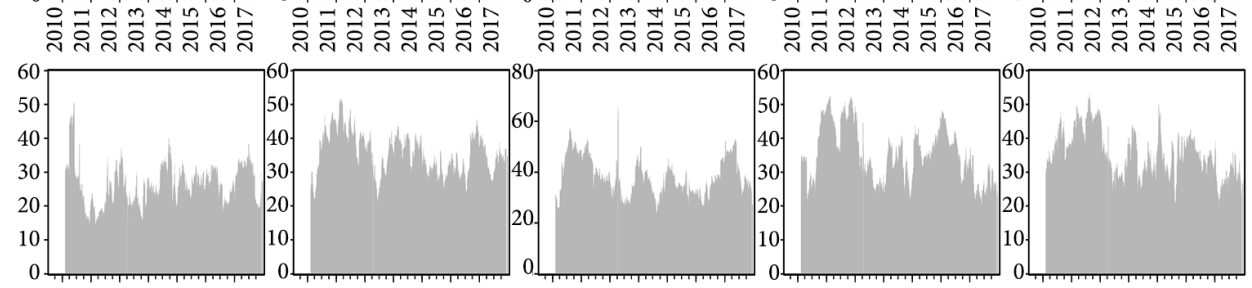

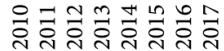

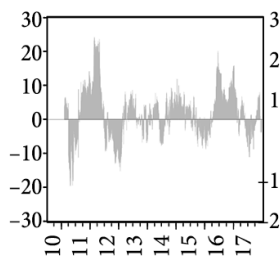

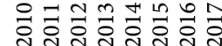
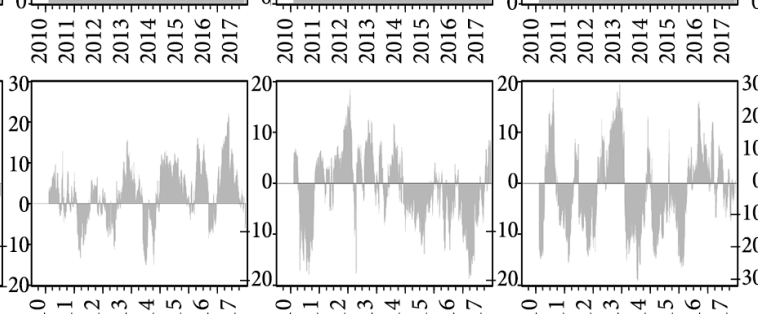

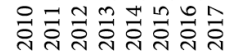

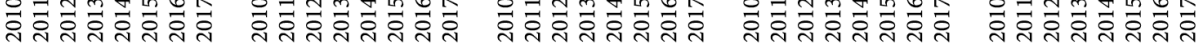

Figure 6. Upper panel: Directional volatility spillovers, direction FROM, from good volatility, middle panel: directional spillovers, direction FROM, from bad volatility, lower panel:

the directional spillover asymmetry measures $S A M_{2 N, i \leftarrow}^{H}$.

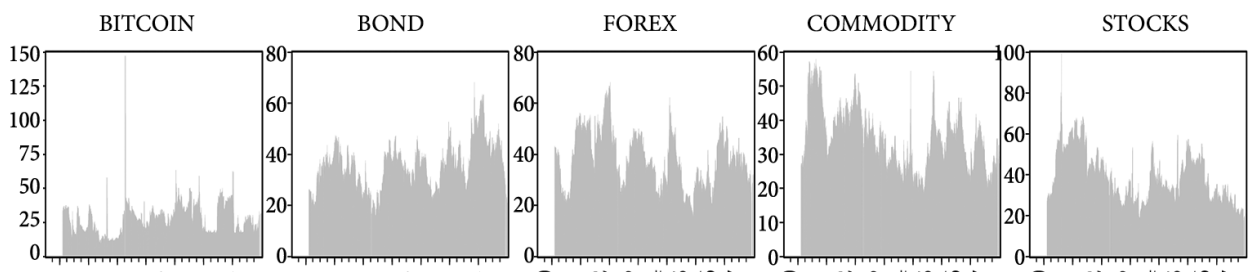

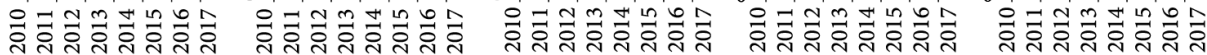

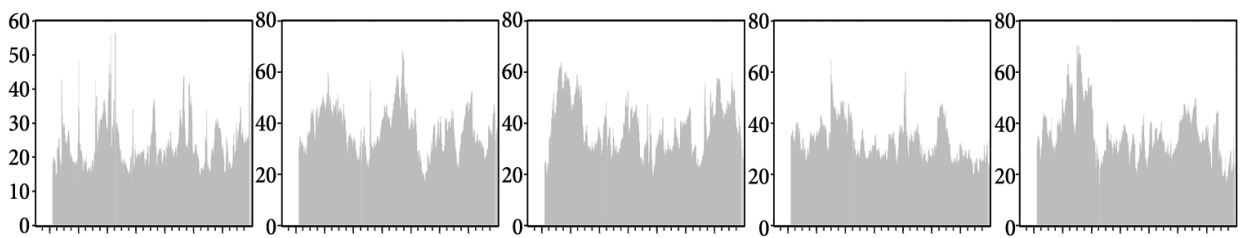

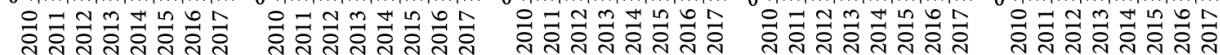

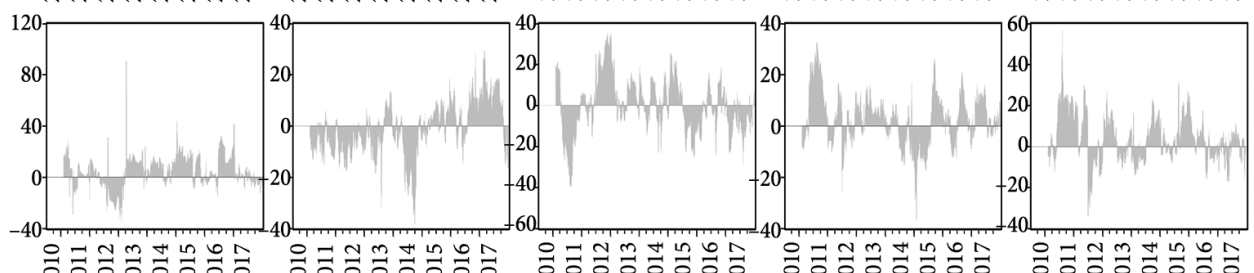

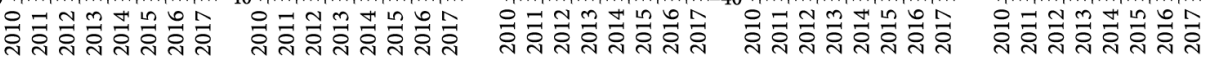

Figure 7. Upper panel: Directional volatility spillovers, direction TO, from good volatility, middle panel: directional spillovers, direction TO, from bad volatility, lower panel: 
market whereas foreign exchange market received (transmitted) net positive volatility spillover from (to) other U.S. financial markets. During the second quarter of 2013 asymmetry is evident due to U.S. FRB taper Tantrum and Cyprus crisis. In this phase Bitcoin and bond market received net negative volatility spillover whereas Foreign exchange, commodity and stock market received net positive volatility spillover from other U.S. financial markets. Bond was the only market that transmitted net negative volatility spillover to other U.S. financial markets during this phase.

The fourth phase of asymmetric volatility spillover in the year 2014 was due to oil prices shock, the Russian crisis and worsening conditions of the Euro-zone troubled economies. During this period Bitcoin, bond, foreign exchange and stock market received a mix of positive and negative volatility spillover whereas commodity market suffered from receipt of net negative volatility. Also, during this phase Bitcoin and foreign exchange market transmitted net positive volatility spillover, whereas bond, commodity and stock market transmitted net negative volatility spillover to other U.S. markets analysed. The crash of Shanghai stock exchange and European stock market turbulence also depict asymmetry in the spillover among the U.S. Bitcoin and financial markets. The Brexit announcement on June 23 and Chinese reform initiative in August of 2016 depict the fifth phase of asymmetric volatility spillover among the U.S. Bitcoin and financial markets. During this phase Bitcoin, bond and stock markets was the receiver of net positive volatility spillover from other U.S. markets, whereas foreign exchange and commodity market experienced transmission of net negative volatility spillover from U.S. Bitcoin and financial markets. During this phase all the analysed markets transmitted net positive volatility spillover to other markets in the sample. During the year 2017 Bitcoin, foreign exchange and stock market received net negative volatility spillover from other markets whereas bond and commodity markets received net positive volatility spillover. On the other side, Bond, commodity and stock market transmitted net positive volatility spillover whereas foreign exchange market transmitted net negative volatility spillover. For Bitcoin the spillover to and from other market was very low.

\subsection{Frequency connectedness}

The interconnectedness between U.S. Bitcoin and financial markets at short and long frequencies is depicted in Table 4 and Figure 8. Table 4 reveals the static measure of frequency connectedness within and absolute frequency domain, whereas Figure 8 depicts the time varying nature of connectedness between U.S. Bitcoin and financial markets at short and long frequencies.

Table 4 indicates that Bitcoin market has the lowest connectedness at both short and long frequencies with the U.S. financial markets, whereas stock market has the highest connectedness at short frequency and commodity market at long frequency. Moreover the average connectedness among the U.S. Bitcoin and financial market is higher at the short frequency $(11.36 \%)$ as compared to long frequency $(9.82 \%)$. This clearly indicates that volatility spillover is more dominant over the short frequency among the U.S. Bitcoin and financial markets. The rolling window frequency connected at short and long frequencies is depicted in Figure 8. The graph reveals that short frequency spillover plays a dominant role in the overall spillover during the entire sample period. At occasions the dominant role of short frequency 
Table 4. Frequency domain spillover table for U.S. bitcoin and financial markets

\begin{tabular}{|l|c|c|c|c|c|c|c|}
\hline \multicolumn{1}{|c|}{ Short } & Bitcoin & Bond & Forex & Commodity & Stock & FROM ABS & FROM WTH \\
\hline Bitcoin & 27.50 & 0.03 & 0.13 & 0.17 & 0.20 & 0.11 & 0.21 \\
\hline Bond & 0.19 & 51.91 & 0.87 & 1 & 4.61 & 1.34 & 2.61 \\
\hline Forex & 0.17 & 0.87 & 51.42 & 2.72 & 1.67 & 1.09 & 2.12 \\
\hline Commodity & 0.14 & 1.13 & 2.58 & 47.09 & 3.35 & 1.44 & 2.81 \\
\hline Stock & 0.05 & 3.86 & 1.53 & 3.85 & 49.47 & 1.86 & 3.62 \\
\hline TO ABS & 0.11 & 1.18 & 1.02 & 1.55 & 1.97 & 5.83 & \\
\hline TO WTH & 0.22 & 2.30 & 1.99 & 3.02 & 3.83 & & 11.36 \\
\hline \multicolumn{1}{|c|}{ Long } & Bitcoin & Bond & Forex & Commodity & Stock & FROM ABS & FROM WTH \\
\hline Bitcoin & 71.72 & 0.03 & 0.15 & 0.03 & 0.05 & 0.1 & 0.1 \\
\hline Bond & 0.12 & 37.03 & 0.84 & 0.55 & 2.87 & 0.88 & 1.80 \\
\hline Forex & 0.15 & 0.95 & 38.34 & 2.61 & 1.08 & 0.96 & 1.97 \\
\hline Commodity & 0.52 & 0.34 & 2.65 & 37.57 & 4.62 & 1.63 & 3.34 \\
\hline Stock & 0.02 & 2.94 & 0.82 & 2.56 & 34.91 & 1.27 & 2.61 \\
\hline TO ABS & 0.16 & 0.85 & 0.89 & 1.15 & 1.72 & 4.78 & \\
\hline TO WTH & 0.33 & 1.75 & 1.83 & 2.37 & 3.54 & & 9.82 \\
\hline
\end{tabular}

Note: Table shows the estimated spillover for the U.S. Bitcoin and Financial markets, estimated using the Barunik and Krehlik (2018) methodology. ABS and WTH refers to absolute and within the estimated system. The spillover table has 2 frequency bands. The spillover table (Upper panel) for band: 3.14 to 0.79 (short), roughly corresponds to 1 day to 4 days. The spillover table (Lower Panel) for band: 0.79 to 0.00 (Long) roughly corresponds to 4 days to infinite days.

Frequency decomposition

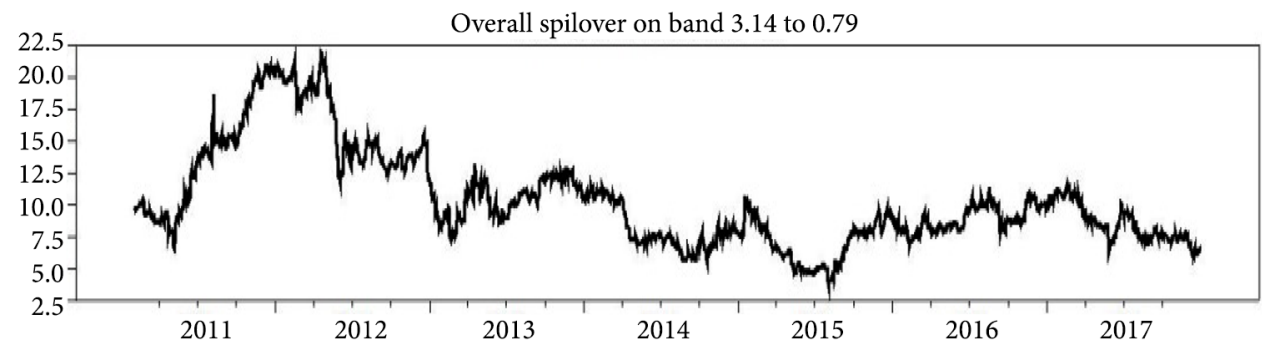

Overall spilover on band 0.79 to 0.00

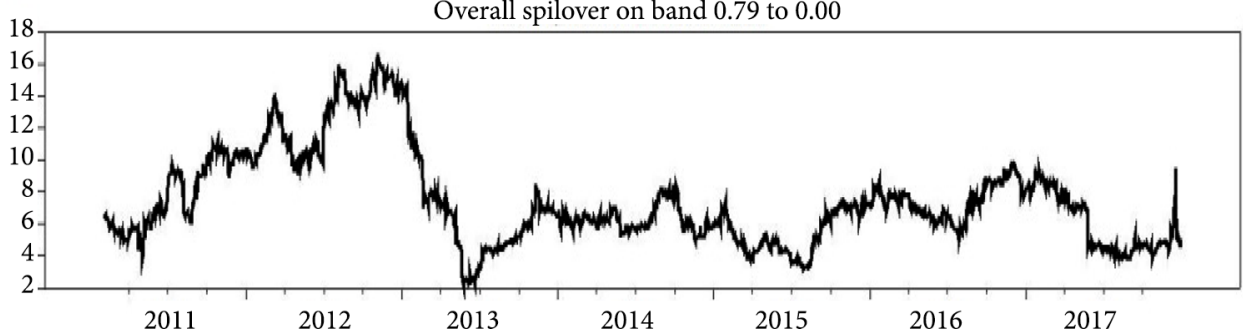

Figure 8. Dynamic frequency connectedness of the U.S. Bitcoin and financial markets on frequency bands. Upper plot presents frequency connectedness for the frequency band $d_{1} \in[1,4]$ days (Short Horizon) and the lower plot presents frequency connectedness for the frequency band $d_{2} \in[4, \infty]$ days (Long Horizon) 
spillover has been taken by long frequency spillover that is most evident during third quarter of 2012 up to third quarter of 2013 due to increased severity of Eurozone crisis. Long frequency dominance is also revealed during August to October 2014 at time when major European stock markets collapsed. Another major dominance of long frequency spillover is evident at the end of the same period during the $4^{\text {th }}$ quarter of 2017 due the uncertainty created in the global financial markets after the German newspaper "Süddeutsche Zeitung" published 13.4 million documents related offshore financial activities of politicians, corporate giants and business leaders. Overall picture of frequency connectedness reveals that investors in the U.S. Bitcoin and financial markets process information quickly and the spillover is more evident within the short horizon.

\section{Conclusions}

The aim of the present study was to examine the dynamics of volatility spillover between U.S. Bitcoin and financial markets. The findings of Diebold and Yilmaz (2012), spillover index, Barunik et al. (2017) Spillover Asymmetry Measure and Barunik and Krehlik (2018) frequency connectedness methodologies, indicated evidence of low integration, asymmetric volatility spillover and dominant role of short frequency connectedness among the U.S. Bitcoin and financial markets, with time varying patterns in response to various domestic and global events. The findings also indicated a decrease in integration of U.S. financial markets due to the presence of Bitcoin markets. Moreover, the volatility spillover among the U.S. Bitcoin and financial markets depicted asymmetric behaviour and was found to be more dominated by short frequency connectedness. The dominant role of short frequency connectedness indicated the short horizon of spillover among the studied markets that can be informative for investors and academic researchers.

Bitcoin's unprecedented rise and investor's increased confidence catalyse the accelerated growth of Crypto-currencies. Believing on what history suggested that the more rapid is the appreciation, the more rapid will be the depreciation. Bitcoin, even after losing more than half of its value (from $\$ 19,800$ to around $\$ 8,000$ per coin), is still experiencing downward trajectory over time. Nonetheless, these worrying forecasts, Bitcoin collapse is unlikely to have any significant impact on financial markets. Among many reasons accounted for Bitcoin bubbles to be potentially non-destructive, the most imperative suggested that cryptocurrencies need to be far more embraced to gain a much greater share of leveraged investors' assets, in order to affect other financial markets.

The overall findings concluded that, with increasing popularity and tradability of Bitcoin, it is expected to impact other U.S. financial markets, which can be substantial in the future. With change in dynamics of global financial markets, the U.S. Bitcoin and financial markets' integration vary, thus providing evidence of its responsive behaviour to various global economic events. These findings provide useful implication for U.S. investors, portfolio managers, and researchers, who can take advantage of low level of integration between the U.S. Bitcoin and financial markets and thus utilize the hedging capabilities that Bitcoin offer. The Bitcoin market is newly established; therefore historical data for Bitcoin is limited back to July, 2010, creating a lower bound on the analysis period. The limitation on histori- 
cal data prevented us from analysing the spillover behaviour between U.S. financial markets and Bitcoin during periods of turmoil in conventional and alternative assets' markets. As future line of work, academicians and researchers are encouraged to explore the factors affecting the integration and contagion among U.S. Bitcoin and financial markets. Moreover, an investigation into the integration and spillover dynamics of other crypto-currencies and U.S. financial markets/global financial markets could be an exciting future work to pursue. It is also suggested to perform a micro-level spillover analysis between crypto-currencies, U.S. industrial sectors, foreign exchange pairs, fixed income securities and alternative investments.

\section{Acknowledgements}

The authors are very grateful for the insightful comments and suggestions of the anonymous reviewers.

\section{Funding}

No funding has been for provided for carrying out this research.

\section{Author contributions}

Muhammad Owais Qarni and Saqib Gulzar conceived the idea of the study and Muhammad Owais Qarni worked under the supervision of Saqib Gulzar for design, development of the data analysis, data collection, analysis, interpretation and writing of the first draft. Syeda Tamkeen Fatima, Majid Jamal Khan and Khurram Shafi reviewed the draft after revision and carried out the additional analysis recommended by reviewers.

\section{Disclosure statement}

The authors do not have any competing financial, professional, or personal interests from other parties.

\section{References}

Aktan, B., Korsakienè, R., \& Smaliukiene, R. (2010). Time-varying volatility modelling of Baltic stock markets. Journal of Business Economics and Management, 11(3), 511-532. https://doi.org/10.3846/jbem.2010.25

Antonakakis, N. (2012). Exchange return co-movements and volatility spillovers before and after the introduction of euro. Journal of International Financial Markets, Institutions and Money, 22(5), 1091-1109. https://doi.org/10.1016/j.intfin.2012.05.009

Authority, E. B. (2014). Eba opinion on virtual currencies. Retrieved from https://www. eba. europa. eu/ documents/10180/657547/EBA-Op-2014-08+ Opinion+ on+ Virtual+ Currencies. pdf

Barunik, J., \& Krehlik, T. (2016). Measuring the frequency dynamics of financial and macroeconomic connectedness (No. 54). FinMaP-Working Paper. 
Barunik, J., \& Křehlík, T. (2018). Measuring the frequency dynamics of financial connectedness and systemic risk. Journal of Financial Econometrics, 16(2), 271-296. https://doi.org/10.1093/jjinec/nby001

Barunik, J., Kocenda, E., \& Vacha, L. (2015). Volatility spillovers across petroleum markets. William Davidson Institute Working Paper No. 1093. https://doi.org/10.2139/ssrn.2600204

Barunik, J., Kočenda, E., \& Vácha, L. (2017). Asymmetric volatility connectedness on the Forex market. Journal of International Money and Finance, 77, 39-56. https://doi.org/10.1016/j.jimonfin.2017.06.003

Baur, D. G., Hong, K., \& Lee, A. D. (2018). Bitcoin: Medium of exchange or speculative assets? Journal of International Financial Markets, Institutions and Money, 54, 177-189. https://doi.org/10.1016/j.intfin.2017.12.004

Bouri, E., Jalkh, N., Molnár, P., \& Roubaud, D. (2017a). Bitcoin for energy commodities before and after the December 2013 crash: diversifier, hedge or safe haven? Applied Economics, 49(50), 5063-5073. https://doi.org/10.1080/00036846.2017.1299102

Bouri, E., Molnár, P., Azzi, G., Roubaud, D., \& Hagfors, L. I. (2017b). On the hedge and safe haven properties of bitcoin: Is it really more than a diversifier? Finance Research Letters, 20, 192-198. https://doi.org/10.1016/j.frl.2016.09.025

Bouri, E., Gupta, R., Tiwari, A., \& Roubaud, D. (2017c). Does bitcoin hedge global uncertainty? Evidence from wavelet-based quantile-in-quantile regressions. Finance Research Letters, 000, 1-9. https://doi.org/10.1016/j.frl.2017.02.009

Brunnermeier, M. K., \& Pedersen, L. H. (2008). Market liquidity and funding liquidity. The Review of Financial Studies, 22(6), 2201-2238. https://doi.org/10.1093/rfs/hhn098

Bubak, V., Kočenda, E., \& Žikeš, F. (2011). Volatility transmission in emerging European foreign exchange markets. Journal of Banking \& Finance, 35(11), 2829-2841. https://doi.org/10.1016/j.jbankfin.2011.03.012

Cheah, E. T., \& Fry, J. (2015). Speculative bubbles in Bitcoin markets? An empirical investigation into the fundamental value of Bitcoin. Economics Letters, 130, 32-36. https://doi.org/10.1016/j.econlet.2015.02.029

Cheung, A., Roca, E., \& Su, J. J. (2015). Crypto-currency bubbles: an application of the Phillips-Shi-Yu (2013) methodology on Mt. Gox bitcoin prices. Applied Economics, 47(23), 2348-2358. https://doi.org/10.1080/00036846.2015.1005827

Coindesk. (2017). Bitcoin Price Index. Retrieved from https://www.coindesk.com/price/bitcoin

Demir, E., Gozgor, G., Lau, C. K. M., \& Vigne, S. A. (2018). Does economic policy uncertainty predict the Bitcoin returns? An empirical investigation. Finance Research Letters. https://doi.org/10.1016/j.frl.2018.01.005

Dew-Becker, I., \& Giglio, S. (2016). Asset pricing in the frequency domain: theory and empirics. The Review of Financial Studies, 29(8), 2029-2068. https://doi.org/10.1093/rfs/hhw027

Diebold, F. X., \& Yilmaz, K. (2012). Better to give than to receive: Predictive directional measurement of volatility spillovers. International Journal of Forecasting, 28(1), 57-66. https://doi.org/10.1016/j.ijforecast.2011.02.006

Dwyer, G. P. (2015). The economics of Bitcoin and similar private digital currencies. Journal of Financial Stability, 17, 81-91. https://doi.org/10.1016/j.jfs.2014.11.006

Dyhrberg, A. H. (2016a). Bitcoin, gold and the dollar - A GARCH volatility analysis. Finance Research Letters, 16, 85-92. https://doi.org/10.1016/j.frl.2015.10.008

Dyhrberg, A. H. (2016b). Hedging capabilities of bitcoin. Is it the virtual gold?. Finance Research Letters, 16, 139-144. https://doi.org/10.1016/j.frl.2015.10.025

Ehrmann, M., Fratzscher, M., \& Rigobon, R. (2011). Stocks, bonds, money markets and exchange rates: measuring international financial transmission. Journal of Applied Econometrics, 26(6), 948-974. https://doi.org/10.1002/jae.1173 
Force, F. A. T. (2014). Virtual currencies: key definitions and potential AML/CFT risks. FATF Report, June.

Guesmi, K., Saadi, S., Abid, I., \& Ftiti, Z. (2018). Portfolio diversification with virtual currency: Evidence from bitcoin. International Review of Financial Analysis. https://doi.org/10.1016/j.irfa.2018.03.004

Gulzar, S., Kayani, G. M., Feng, H. X. Ayub, U., \& Rafique, A. (2019). Financial cointegration and spillover effect of global financial crisis: A study of emerging Asian financial markets. Economic Research - Ekonomska Istraživanja.

Investing. (2017). Market indices. Retrieved from https://www.investing.com/indices/

Katsiampa, P. (2017). Volatility estimation for Bitcoin: A comparison of GARCH models. Economics Letters, 158, 3-6. https://doi.org/10.1016/j.econlet.2017.06.023

Kerner, S. (2014). Why Marc Andreessen is Bullish on Bitcoin. Eweek, 3.

Kim, B. H., Kim, H., \& Lee, B. S. (2015). Spillover effects of the US financial crisis on financial markets in emerging Asian countries. International Review of Economics \& Finance, 39, 192-210. https://doi.org/10.1016/j.iref.2015.04.005

King, M. A., \& Wadhwani, S. (1990). Transmission of volatility between stock markets. The Review of Financial Studies, 3(1), 5-33. https://doi.org/10.1093/rfs/3.1.5

Kodres, L. E., \& Pritsker, M. (2002). A rational expectations model of financial contagion. The Journal of Finance, 57(2), 769-799. https://doi.org/10.1111/1540-6261.00441

Koop, G., Pesaran, M. H., \& Potter, S. M. (1996). Impulse response analysis in nonlinear multivariate models. Journal of econometrics, 74(1), 119-147. https://doi.org/10.1016/0304-4076(95)01753-4

Kurihara, Y., \& Fukushima, A. (2017). The market efficiency of Bitcoin: A weekly anomaly perspective. Journal of Applied Finance and Banking, 7(3), 57.

Nadarajah, S., \& Chu, J. (2017). On the inefficiency of Bitcoin. Economics Letters, 150, 6-9. https://doi.org/10.1016/j.econlet.2016.10.033

Pesaran, H. H., \& Shin, Y. (1998). Generalized impulse response analysis in linear multivariate models. Economics letters, 58(1), 17-29. https://doi.org/10.1016/S0165-1765(97)00214-0

Phillips, P. C., \& Yu, J. (2011). Dating the timeline of financial bubbles during the subprime crisis. Quantitative Economics, 2(3), 455-491. https://doi.org/10.3982/QE82

Qarni, M. O., \& Gulzar, S. (2018). Volatility spillover effects of Shanghai stock exchange crash on the stock markets of its major trading partners. Business \& Economic Review, 10(3), 1-28.

Raghunathan, S. (2015). Volatility in Indian stock market. Asian Journal of Research in Business Economics and Management, 5(2), 298-311. https://doi.org/10.5958/2249-7307.2015.00049.3

Richardson, V. (2014). Currency kings. Entrepreneur, 42, 40.

Rogers, L. C. G., \& Satchell, S. E. (1991). Estimating variance from high, low and closing prices. The Annals of Applied Probability, 504-512. https://doi.org/10.1214/aoap/1177005835

Selgin, G. (2015). Synthetic commodity money. Journal of Financial Stability, 17, 92-99. https://doi.org/10.1016/j.jfs.2014.07.002

Urquhart, A. (2017). Price clustering in Bitcoin. Economics Letters, 159, 145-148. https://doi.org/10.1016/j.econlet.2017.07.035

Yarovaya, L., Brzeszczyński, J., \& Lau, C. K. M. (2016). Intra-and inter-regional return and volatility spillovers across emerging and developed markets: Evidence from stock indices and stock index futures. International Review of Financial Analysis, 43, 96-114. https://doi.org/10.1016/j.irfa.2015.09.004

Yusoff, M. B., \& Sabit, A. H. (2015). The effects of exchange rate volatility on ASEAN-China bilateral exports. Journal of Economics, Business and Management, 3(5), 479-482.

https://doi.org/10.7763/JOEBM.2015.V3.231 